\title{
Minerals Form a Continuum Phase in Mature Cancellous Bone
}

\author{
Po-Yu Chen • Damon Toroian · Paul A. Price • \\ Joanna McKittrick
}

Received: 10 November 2010/Accepted: 29 December 2010/Published online: 28 January 2011

(C) The Author(s) 2011. This article is published with open access at Springerlink.com

\begin{abstract}
Bone is a hierarchically structured composite consisting of a protein phase (type I collagen) and a mineral phase (carbonated apatite). The objective of this study was to investigate the hierarchical structure of mineral in mature bone. A method to completely deproteinize bone without altering the original structure is developed, and the completion is confirmed by protein analysis techniques. Stereoscopy and field emission electron microscopy are used to examine the structural features from submillimeterto micrometer- to nanometer-length scales of bovine femur cancellous bone. Stereoscopic images of fully deproteinized and demineralized bovine femur cancellous bone samples show that fine trabecular architecture is unaltered and the microstructural features are preserved, indicating the structural integrity of mineral and protein constituents. SEM revealed that bone minerals are fused together and
\end{abstract}

The authors have stated that they have no conflict of interest.

P.-Y. Chen $(\bowtie) \cdot$ J. McKittrick

Materials Science and Engineering Program,

Department of Mechanical and Aerospace Engineering,

University of California, San Diego, 9500 Gilman Drive,

La Jolla, CA 92093-0411, USA

e-mail: pochen@ucsd.edu

J. McKittrick

e-mail: jmckittrick@ucsd.edu

D. Toroian · P. A. Price

Division of Biological Sciences, University of California,

San Diego, 9500 Gilman Drive, La Jolla,

CA 92093-0322, USA

e-mail: dtoroian@gmail.com

P. A. Price

e-mail: pprice@ucsd.edu form a sheet-like structure in a coherent manner with collagen fibrils. Well-organized pore systems are observed at varying hierarchical levels. Mineral sheets are peeled off and folded after compressive deformation, implying strong connection between individual crystallites. Results were compared with commercially available heat-deproteinized bone (Bio-Oss ${ }^{\circledR}$ ), and evidence showed consistency in bone mineral structure. A two-phase interpenetrating composite model of mature bone is proposed and discussed.

Keywords Bone - Mineral - Hierarchical structure . Biomineralization · Composite $\cdot$ Electron microscopy

Bone is a composite material of a protein (mainly type I collagen), a mineral phase (carbonated hydroxyapatite), and water assembled into a complex, hierarchical structure. The hierarchical structure of bone has been reviewed by several groups [1-4]. This article will focus on the hierarchical structure of the mineral constituents in bone.

Mammalian skeletal bone is made up of around $65 \mathrm{wt} \%$ mineral phase, $25 \mathrm{wt} \%$ organic material, and $10 \mathrm{wt} \%$ water. On a volumetric basis, bone consists of about 33-43 vol.\% minerals, 32-44 vol.\% organic material, and 15-25 vol.\% water [5]. Type I collagen is the major organic component of bone and has a specific hierarchical arrangement. Tropocollagen is formed from the association of two alpha-1 and one alpha- 2 collagen molecules, which assemble into a triple helix $\sim 1.5 \mathrm{~nm}$ in diameter and $300 \mathrm{~nm}$ in length. Tropocollagen molecules assemble into a staggered arrangement with a periodicity of $67 \mathrm{~nm}$, which consists of a gap region and an overlap region. This periodicity produces a characteristic interference pattern that is observed as bands in transmission electron microscopy (TEM). Bone minerals consist of nonstoichiometric hydroxyapatite crystals- 
chemical formula $\mathrm{Ca}_{10}\left(\mathrm{PO}_{4}\right)_{6}(\mathrm{OH})_{2}$-with $4-6 \%$ of the phosphate groups replaced by carbonate groups. The bone crystals are in the form of platelets approximately 40-60 nm in length and 20-30 $\mathrm{nm}$ in width. The thickness of bone crystals measured from TEM [6-9] and small-angle X-ray scattering (SAXS) $[10,11]$ varies from $1.5 \mathrm{~nm}$ for mineralized tendon to $4 \mathrm{~nm}$ for some mature bones. Recent atomic force microscopy (AFM) studies found that the bone crystals are longer than those observed by TEM, with widths and lengths ranging from 30 to $200 \mathrm{~nm}[12,13]$. This discrepancy may due to breakage of the fragile crystallites during TEM sample preparation.

Most studies on the structural organization of mineral within collagen fibrils have been carried out on mineralized turkey leg tendon (MTLT) [14-19]. TEM observations of individual MTLTs showed that mineral crystals are organized in layers that transverse across the fibrils with the crystallographic $c$-axis aligned parallel with the fibril long axis [14-16]. The 67-nm periodicity of mineralized collagen fibrils shown in TEM indicated that the minerals have the same staggered organization as collagen fibrils. AFM [17] and high-voltage 3-D TEM tomography [18, 19] also confirmed the layered arrangement of crystals within collagen fibrils. However, MTLT (mineral content $\sim 43 \mathrm{wt} \%$ ) is not bone, which has a much higher degree of mineralization $(\sim 65 \mathrm{wt} \%)$ and a more complicated structure.

It is generally believed that crystals initially form within the gap region of the collagen fibrils, further proceed into the overlap region, and subsequently grow into the extrafibrillar space [20]. Consequently, mineral is found both within and outside the collagen fibrils, but the exact amount in each location is still a matter of contention [21-25]. Landis and coworkers [18, 19, 26] proposed a model for early-stage mineralization based on the 3-D TEM tomography. The staggered arrangement of collagen fibrils formed extensive channels laterally through the arrays. Mineral crystals developed preferentially in length along the collagen long axes and in width within the spaces generated by the channel. Crystals were fused together and grew in length beyond gap and overlap regions, ranging 40-170 $\mathrm{nm}$ and in width to $\sim 40 \mathrm{~nm}$, well beyond that of individual collagen gap regions. However, the growth in thickness was limited to 4-6 nm. Ultimately, fused mineral crystals formed thin parallel sheets throughout the assemblage of collagen fibrils. In a recent study on mineral crystals in embryonic chick bones, Landis et al. [27] suggested that the mineral sheets may fuse to form a continuous mineral organization.

Jäger and Fratzl [28] proposed a model of a staggered arrangement of mineral platelets circumferentially surrounding a concentric structure of the collagen fibrils based on MTLT. This composite model of mineral plateletreinforced collagen fibril matrix has been widely applied in recent studies on the structure-mechanical property relationships and toughening mechanisms of bone [29-31]. One prediction of this model is that the mineral phase in bone will be disaggregated into individual crystals if the protein phase is completely removed.

However, there is evidence that bone retains its structural integrity after complete deproteinization by heating. Heat-treated deproteinized bovine bone (DBB) has a chemical composition and a structure that are similar to bone mineral and is used as clinical bone graft material. Depending on the temperature of heat treatment, deproteinized bone can be classified into two types: unsintered $\left(<400^{\circ} \mathrm{C}\right)$ and sintered $\left(>400^{\circ} \mathrm{C}\right)$ [32]. Studies [33, 34] have shown that the mineral crystals become denser and more crystalline and grow in length from $\sim 10$ to $\sim 120 \mathrm{~nm}$ at temperatures exceeding $500^{\circ} \mathrm{C}$. Thus, to examine the unaltered mineral organization, sintered bones are not an option. Bio-Oss ${ }^{\circledR}$ (Geistlich Biomaterials, Wolhusen, Switzerland) is a widely used bone grafting material, which is heat-deproteinized $\left(300^{\circ} \mathrm{C}\right)$ bovine femur cancellous bone $[35,36]$. Bio-Oss ${ }^{\circledR}$ demonstrates interconnective pore systems at various hierarchical levels, which result in an overall porosity of $70-75 \%$ that enhances the deposition and growth of new bone into the inner part of graft materials [35]. The fine trabecular structure and well-organized pore system of deproteinized cancellous bovine femur bone remains unaltered after this lower-temperature treatment. Protein-chemical analysis on Bio-Oss ${ }^{\circledR}$ has confirmed there is no protein content to a measurable extent [36]. Benezra-Rosen et al. [37] recently examined the ultrastructure of the Bio-Oss ${ }^{\circledR}$ using fieldemission scanning electron microscopy (SEM) and TEM and reported that the mineral remains in its original structure after heat treatment at the micro- and nanometer scales. They suggested that the mineral phase, like the collagen matrix, is continuous. However, whether or not the heating may have caused fusion in the mineral phase or altered the original mineral structure remains uncertain.

Our hypothesis is that minerals in mature bone are fused together, forming a continuous architecture. In this study, we employed an entirely different method to completely deproteinize fully developed mature bone with sodium hypochlorite $(\mathrm{NaOCl})$ [7] and then examined the structural organization of bone mineral at varying hierarchical levels, from macrometer- to micrometer- to nanometer-length scales. The well-studied and more readily available cancellous bovine femur was used in this study in order to compare with previous studies on Bio-Oss ${ }^{\circledR}$. The major goals of this study were (1) to develop experimental methods to completely deproteinize bone without altering the original mineral microstructure and confirm the completion using various techniques, (2) to thoroughly investigate the hierarchical structure of the mineral constituents in bone and compare with that of untreated and heat-treated 
bones, and (3) to establish a composite model of bone mineral structure. In this manner, we expect to more fully understand the structure and ultimately the mechanical properties of the mineral constituents in mature bone.

\section{Materials and Methods}

\section{Sample Preparation}

Bovine femur bones were purchased from a local butcher. The slaughter age of the cattle was approximately 18 months. Cancellous bovine femur samples were obtained from the proximal end of the femur using a handsaw. The marrow and blood were carefully removed by running water followed by a dental water jet (Waterpik ${ }^{\circledR}$; Water Pik, Fort Collins, CO). Samples were further precisely machined into rectangles $(7.5 \times 5 \times 5 \mathrm{~mm})$ with the long dimension parallel to the longitudinal (growth) direction of bone using a rotating diamond wheel saw under constant water irrigation. Sectioned cancellous samples were examined under a stereoscope for evidence of damage during preparation. A total of 30 cancellous bovine femur samples were prepared in three conditions (eight untreated, 11 deproteinized, and 11 demineralized samples). Three additional samples were obtained for verifying the completion of deproteinization and demineralization, and the rest of the samples were prepared for structural characterization.

\section{Deproteinization}

Deproteinization was accomplished using a $2.6 \mathrm{wt} \%$ $\mathrm{NaOCl}$ solution at $37^{\circ} \mathrm{C}$. Samples were constantly mixed using a rocking platform [7], and the solution was changed on a daily basis for 14 days. In our earlier studies (not shown here), $2-5 \%$ of protein content remained in the samples after 7 days of deproteinization. We increased the deproteinization time to 14 days to ensure that all of the protein was removed from the samples. In order to verify that the deproteinization was complete, three samples were placed into dialysis sacks (10 kDa MWCO) and dialyzed at room temperature against $0.5 \mathrm{M}$ EDTA $(\mathrm{pH}$ 7.5) until demineralized. Samples were then dialyzed against water to remove EDTA, calcium, and phosphate, then lyophilized and photographed. After dialysis, the mass of protein present in the untreated samples was determined gravimetrically. Gravimetric analysis was not possible for the deproteinized bone samples since there was no detectable material in the lyophilizer flask. To evaluate the possible presence of trace amounts of protein, the flasks from deproteinized bone samples were rinsed with water and the absorbance at $220 \mathrm{~nm}$ was determined. The maximum mass of soluble protein remaining after deproteinization was estimated by assuming that all $220 \mathrm{~nm}$ absorbance was protein $(\mathrm{a} 1-\mathrm{mg} / \mathrm{mL}$ solution of protein has an absorbance at $220 \mathrm{~nm}$ of about 10 ).

\section{Demineralization}

A set of cancellous bovine femur samples was demineralized in order to compare the structural feature of protein constituents with that of mineral constituents. A method for complete demineralization of bone recently developed by Toroian et al. [38] was applied. Samples were submerged in $0.6 \mathrm{~N}$ hydrochloric acid $(\mathrm{HCl})$ at room temperature with constant mixing. The $\mathrm{HCl}$ solution was changed daily, and it took 6 days to fully demineralize the samples. It should be noted that although EDTA has been used to demineralize bone, complete demineralization can require 1 month or more at $37^{\circ} \mathrm{C}$ and, thus, may damage the gross structure of the matrix (possibly due to enzymatic autolysis). We chose $\mathrm{HCl}$ as the demineralization medium since the process is much quicker and, therefore, may minimize damage to the protein structure. Completion of demineralization was confirmed by subsequent deproteinization on the additional samples. Several other samples were ashed at high temperature using the methods developed by Currey and Hughes [39], and the ash weight was used to determine the remaining mass of inorganic components. In all cases, there was no detectable mineral after demineralization. Demineralized samples were dehydrated using standard critical point drying (CPD) before structural characterization in order to avoid any deformation or shrinkage from drying.

\section{Structural Characterization}

The morphology and cellular architecture of cancellous bone were imaged using a stereoscope (W-02400 Binocular Microscope; National Optical, Beaumont, TX) equipped with a CCD camera along with adjustable light sources. Microstructural features were observed using a field emission SEM (FE-SEM) (FEI-XL30; FEI, Hillsboro, OR) in the secondary electron (SE) mode at $20 \mathrm{kV}$ accelerating voltage. Small pieces of cancellous samples were mounted on aluminum sample holders and sputter-coated with a thin layer of gold-platinum. SEM images of the surface of untreated, deproteinized, and demineralized samples at varying magnifications were taken and compared. The fracture surface of untreated and deproteinized samples was observed by SEM. A mechanical testing machine (Instron 3367 Dual Column Testing Systems; Instron, Norwood, MA) was used to fracture the samples under compressive loading at a strain rate of $1 \times 10^{-3} \mathrm{~s}^{-1}$. For the deproteinized samples, two types of fracture surface were created: (1) samples were first fractured, followed 
by deproteinization in order to examine the microstructural organization of the mineral constituents and compare with untreated bone side by side; (2) samples were first deproteinized and then fractured in order to observe the deformed mineral constituents after compressive loading.

\section{Results}

\section{Confirmation of Complete Deproteinization}

An experiment was carried out to determine how much protein remained in samples of cancellous bovine femur after deproteinization in $2.6 \% \mathrm{NaOCl}$ for 14 days. Three deproteinized and three untreated samples were demineralized by dialyzing each against $0.5 \mathrm{M}$ EDTA ( $\mathrm{pH} 7.5)$. This procedure removed all mineral from the bone samples while retaining any protein in the dialysis sack. EDTA, calcium, phosphate, and $\mathrm{NaOCl}$ were removed by subsequent dialysis against distilled water, and the dialysates were lyophilized to dryness.

Visual examination of the three flasks containing the untreated bone samples revealed the presence of a substantial amount of matrix (see Fig. 1a). The volume of demineralized bone matrix was comparable to that of the original bone sample; this result is in agreement with other studies [38]. The mass of dry material remaining in the lyophilizer flasks of the untreated bone samples was $27-29 \%$ of the original bone dry weight prior to demineralization (Table 1), which is comparable to the percentage of dry bone that is protein.

In contrast to the three flasks containing the untreated bone samples, there was no detectable dry material in any of the three flasks containing deproteinized bone samples (Fig. 1b). The mass of dry material remaining in the lyophilizer flasks of the deproteinized bone samples was $0.005-0.01 \%$ of the original bone dry weight based on absorbance at $220 \mathrm{~nm}$ (Table 1). It is likely that this $220 \mathrm{~nm}$ absorbance is not due to protein, however, since alkaline hydrolysates of the material did not stain with ninhydrin (not shown). Based on the detection limit of the ninhydrin assay, the maximum amount of protein remaining in the deproteinized bone samples is $<0.001 \%$ of the protein present in the bone samples prior to deproteinization.

\section{Structural Characterization}

Stereoscopy is an imaging technique capable of generating $3-\mathrm{D}$ visual information and providing depth perception. In this study, stereoscopic imaging was applied to observe the cellular (trabecular) structure, particularly at the submillimeter scale, in cancellous bovine femur samples after demineralization and deproteinization. Cross-sectional and longitudinal stereoscopic images of untreated, deproteinized, and demineralized cancellous bovine femur samples are shown in Fig. 2. The untreated, deproteinized, and demineralized samples had a similar structural morphology. More surprisingly, the fine structure of trabecular network was well preserved after complete deproteinization. A perforated plate structure with channels aligned parallel to the growth direction can be seen in the longitudinal images. Fracture of individual trabecula due to sectioning was occasionally observed on the exposed surface, yet the majority of trabeculae appeared to be undamaged and unaltered throughout the samples. Deproteinized samples turned white due to the $\mathrm{NaOCl}$, while demineralized ones appeared light brown and somewhat transparent. The stereoscopic images showed structural integrity of the mineral and protein constituents in bone at the submillimeter scale.

Figure 3 shows three parallel sets of SEM micrographs from lower to high magnifications taken from the surface of untreated, deproteinized, and demineralized samples. The three groups of samples appear to have similar structural features on the trabecular surface at the submillimeter- and micrometer-length scales. However, the surface topographies are dissimilar at the nanoscale because of
Fig. 1 Photographs showing representative lyophilized samples. a Untreated samples showed proteinaceous residue after lyophilization.

b Deproteinized samples showed no visible evidence of residue
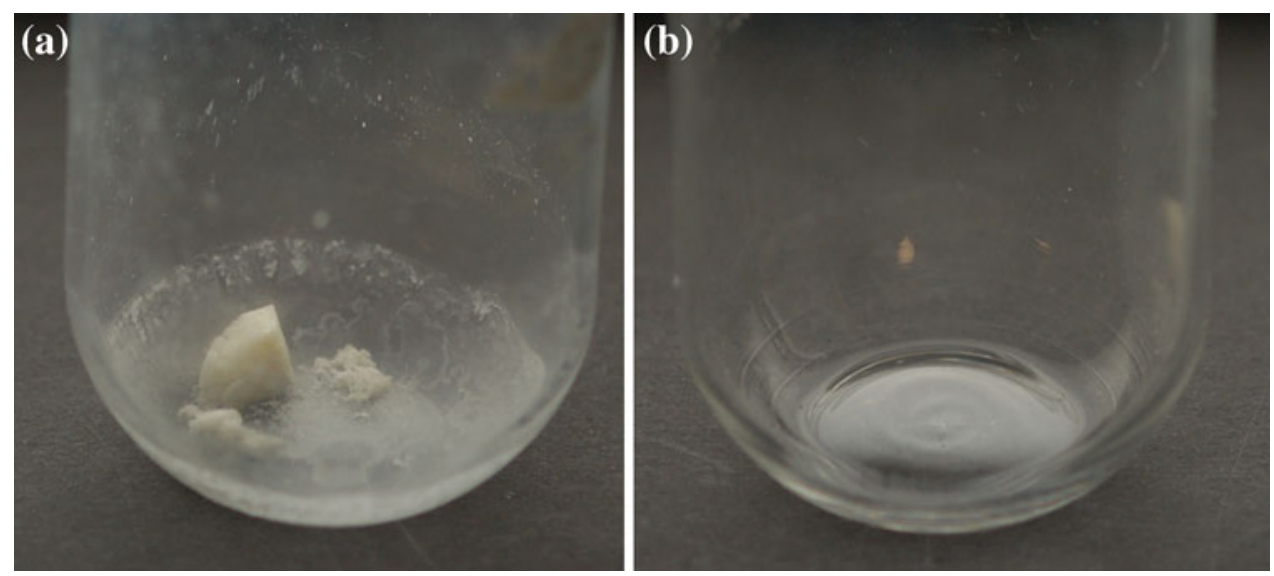
Table 1 Evidence that deproteinization with sodium hypochlorite removes organic components in bone

\begin{tabular}{lll}
\hline $\begin{array}{l}\text { Cancellous bone } \\
\text { sample }\end{array}$ & $\begin{array}{l}\text { Volume of matrix after } \\
\text { demineralization }\end{array}$ & $\begin{array}{l}\text { Wt\% of initial mass remaining } \\
\text { after demineralization }(\%)\end{array}$ \\
\hline Untreated 1 & Comparable to untreated bone & $27.3^{\mathrm{a}}$ \\
Untreated 2 & Comparable to untreated bone & $28.0^{\mathrm{a}}$ \\
Untreated 3 & Comparable to untreated bone & $29.3^{\mathrm{a}}$ \\
Deproteinized 1 & Undetectable & $<0.01^{\mathrm{b}}$ \\
Deproteinized 2 & Undetectable & $<0.005^{\mathrm{b}}$ \\
Deproteinized 3 & Undetectable & $<0.01^{\mathrm{b}}$ \\
\hline
\end{tabular}

Samples were placed into dialysis sacks (10 kDa MWCO) and dialyzed at room temperature against 0.5 M EDTA (pH 7.5) until demineralized. Samples were then dialyzed against water to remove EDTA, calcium, and phosphate and finally lyophilized

${ }^{\text {a }}$ Based on weight of material remaining after demineralization

${ }^{\mathrm{b}}$ Based on absorbance at $220 \mathrm{~nm}$ (see Materials and Methods section)

Fig. 2 Stereoscopic images of bovine femur cancellous bone prior to treatment, after complete deproteinization with sodium hypochlorite, and after complete demineralization with hydrochloric acid

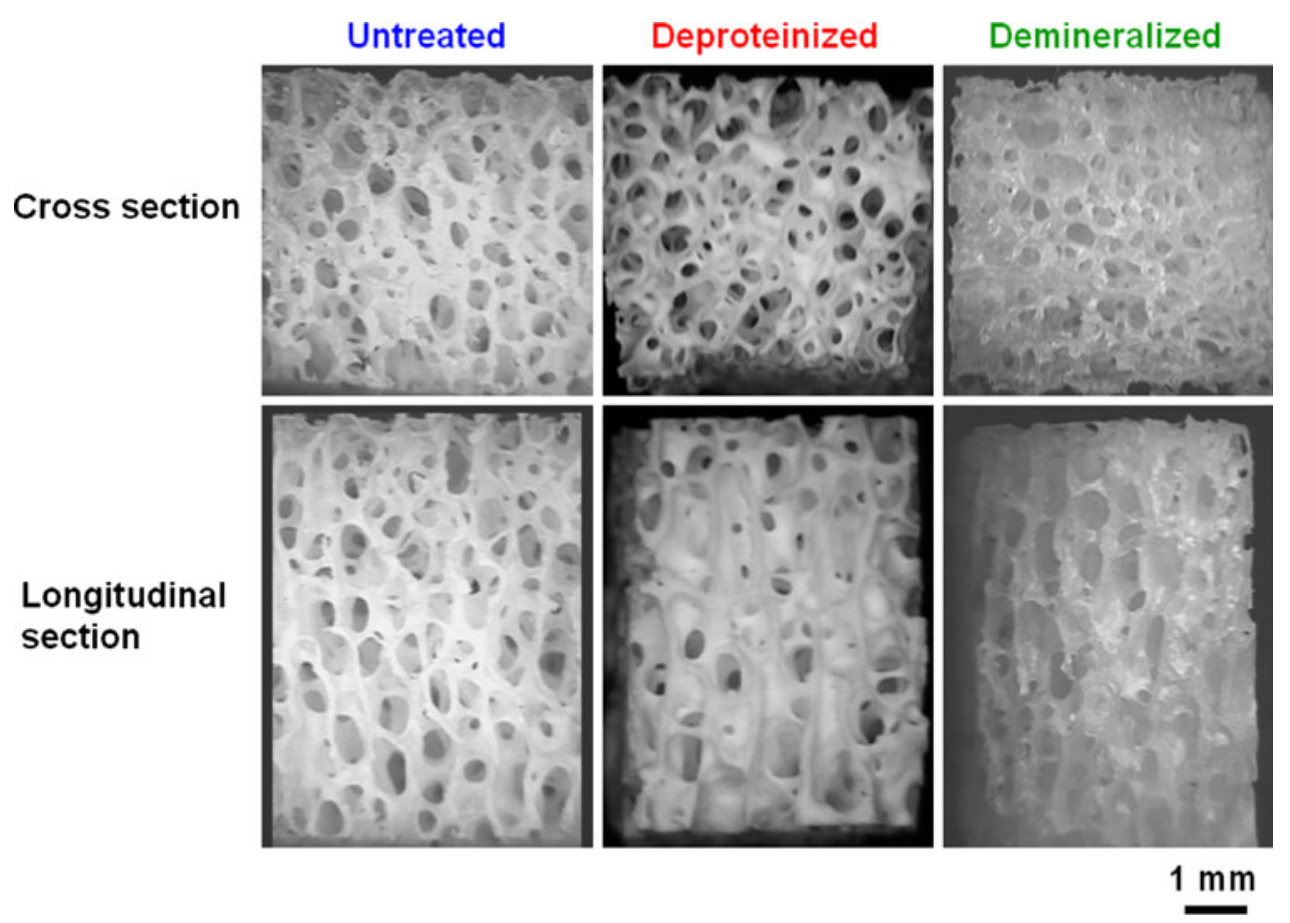

likely the canaliculi connecting osteocytes. The characteristic $67-\mathrm{nm}$ periodicity of mineralized collagen fibers can be observed in the untreated sample and follows a certain preferred orientation along trabeculae, as shown in Fig. 3g.

The fracture surfaces of untreated and deproteinized bone were created and observed by SEM in order to acquire a better understanding of the structural organization of bone minerals associated with collagen fibers. Figure 4a shows the fracture surface of an individual trabecula in an untreated sample after compressive loading. At higher magnification (Fig. 4b), the laminated structure and extensive collagen fiber pull-out can be observed. The collagen fibers are aligned in a preferred orientation along the trabecula. The mineralized collagen fibers form bundles $\sim 1 \mu \mathrm{m}$ in diameter, as shown in Fig. 4c. A close-up view 

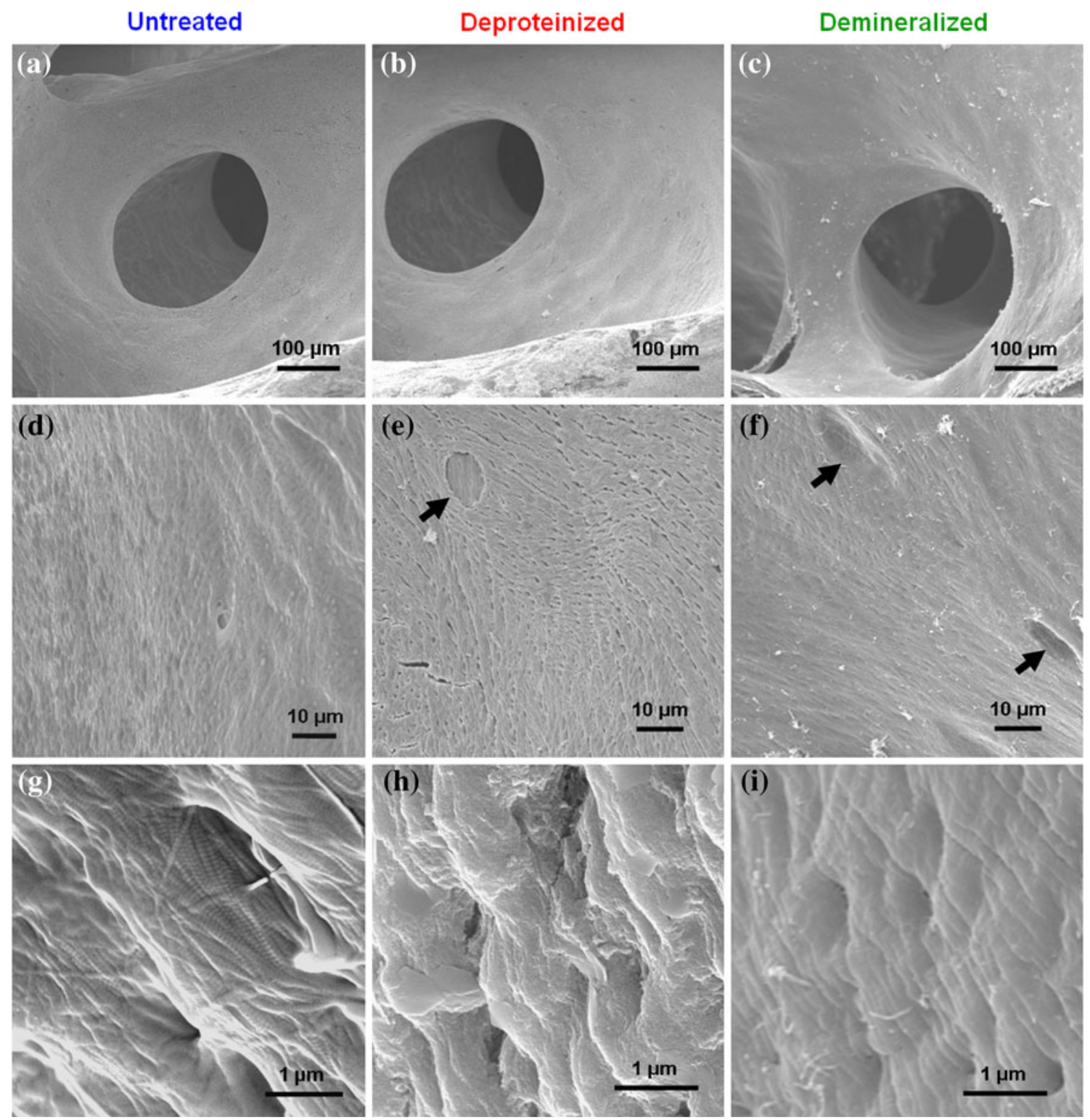

Fig. 3 SEM micrographs showing the surface morphology of untreated (a, d, g), completely deproteinized (b, e, h), and completely demineralized (c, f, i) cancellous bovine femur (arrows indicate osteocyte lacunae)

of individual mineralized collagen fibers $100-150 \mathrm{~nm}$ in diameter can be observed at the highest magnification as shown in Fig. 4d.

Figure 5 shows the fracture surface of a sample first fractured under compression followed by deproteinization. At lowest magnification (Fig. 5a), the fracture surface of trabecula, indicating brittle failure, can be observed. Details of the surface morphology, consisting of ridges and valleys, can be observed in Fig. 5b. The thickness of the mineral sheets measured from several edge-on oriented minerals is $\sim 20 \mathrm{~nm}$, and the length and width range from hundreds of nanometers to several micrometers, as shown in Fig. 5d. The minerals are aligned in a preferred orientation along the longitudinal axis of trabecula. The spacing between two adjacent mineral sheets is approximately $100-150 \mathrm{~nm}$, indicating that minerals locate in the space between parallel collagen fibers, as shown in Fig. 4d. Well-organized channels parallel to the mineral sheets, where collagen fibers may be located, can also be observed.

SEM micrographs taken from a sample which was first deproteinized and then fractured under compression are shown in Fig. 6. Osteocyte lacunae $\sim 10 \mu \mathrm{m}$ in diameter and the well-organized porous channels can be observed on the surface of trabeculae (Fig. 6a, b), similar to those shown in Fig. 3e. At higher magnifications (Fig. 6c, d), a striking feature of the mineral constituents was observed. The mineral 
Fig. 4 SEM micrographs showing the fracture surface of untreated cancellous bovine femur fractured under compression
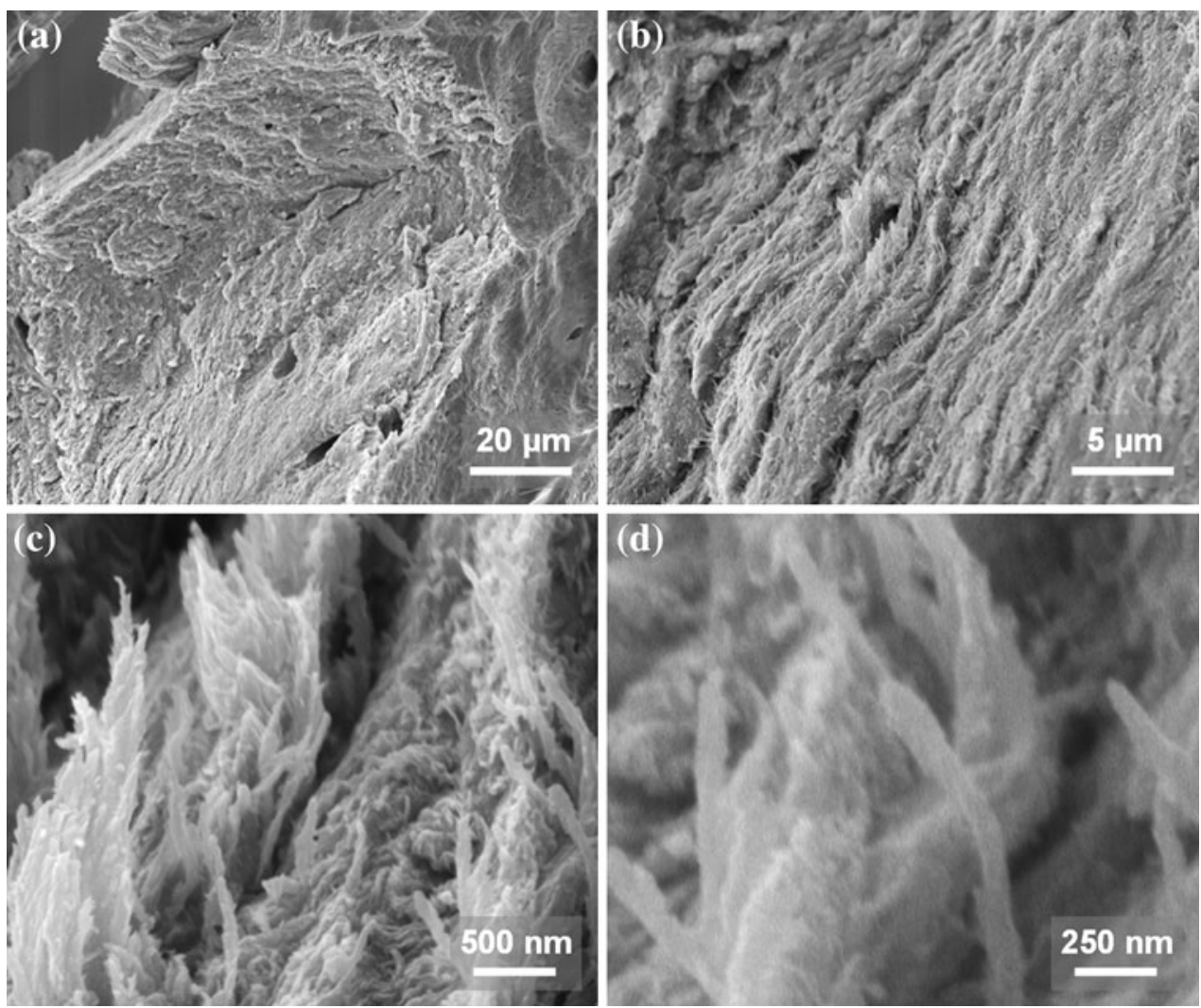

Fig. 5 SEM micrographs showing the fracture surface of deproteinized cancellous bovine femur fractured under compression, then deproteinization
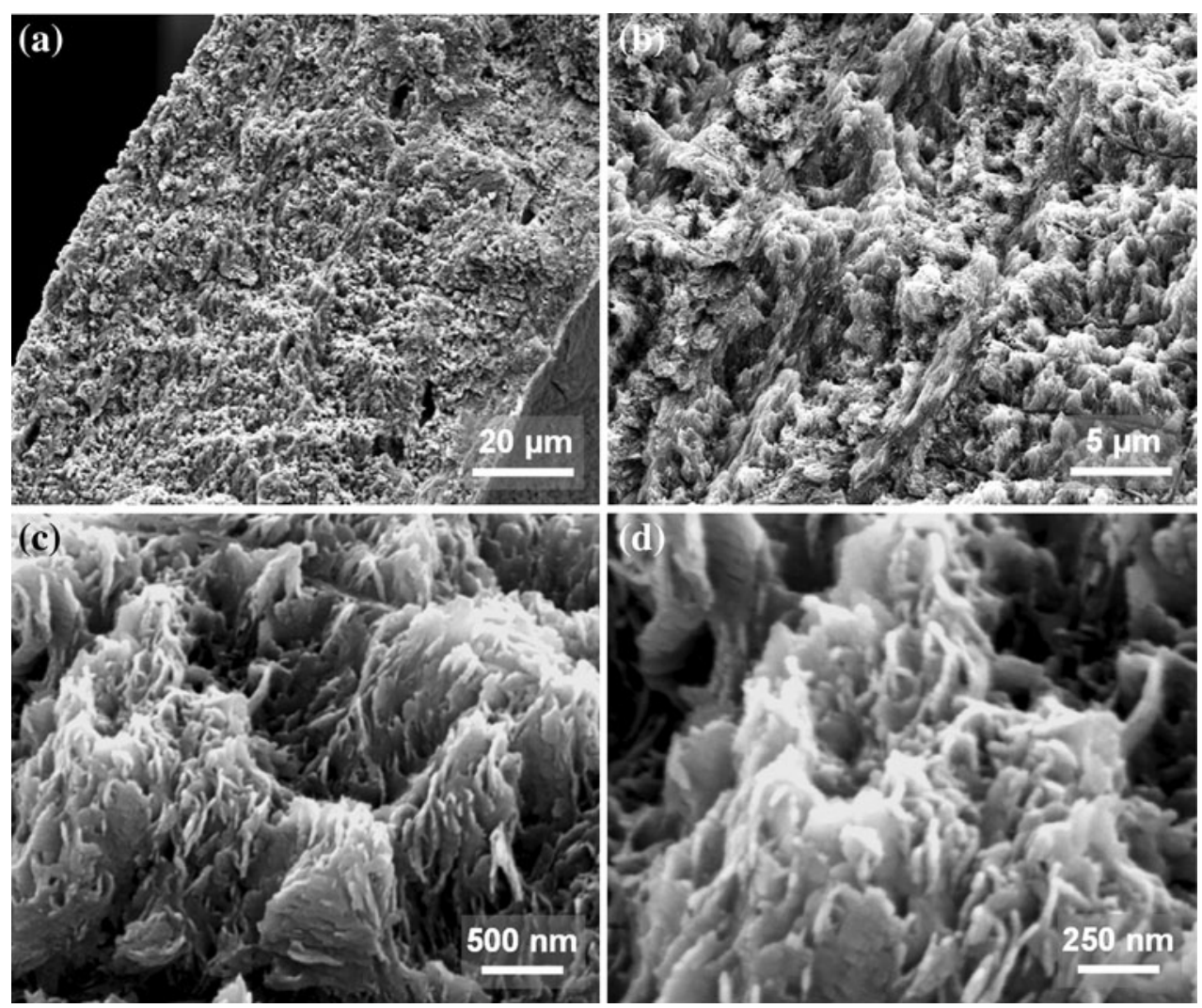
Fig. 6 SEM micrographs showing the surface of deproteinized cancellous bovine femur fractured under compression after deproteinization: a fracture surface of trabeculae showing osteocyte lacunae, $\mathbf{b}$ aligned mineral constituents and porous channels, c deformed mineral sheets on the surface, and d detail structure of the deformed mineral sheets $\sim 20 \mathrm{~nm}$ in thickness
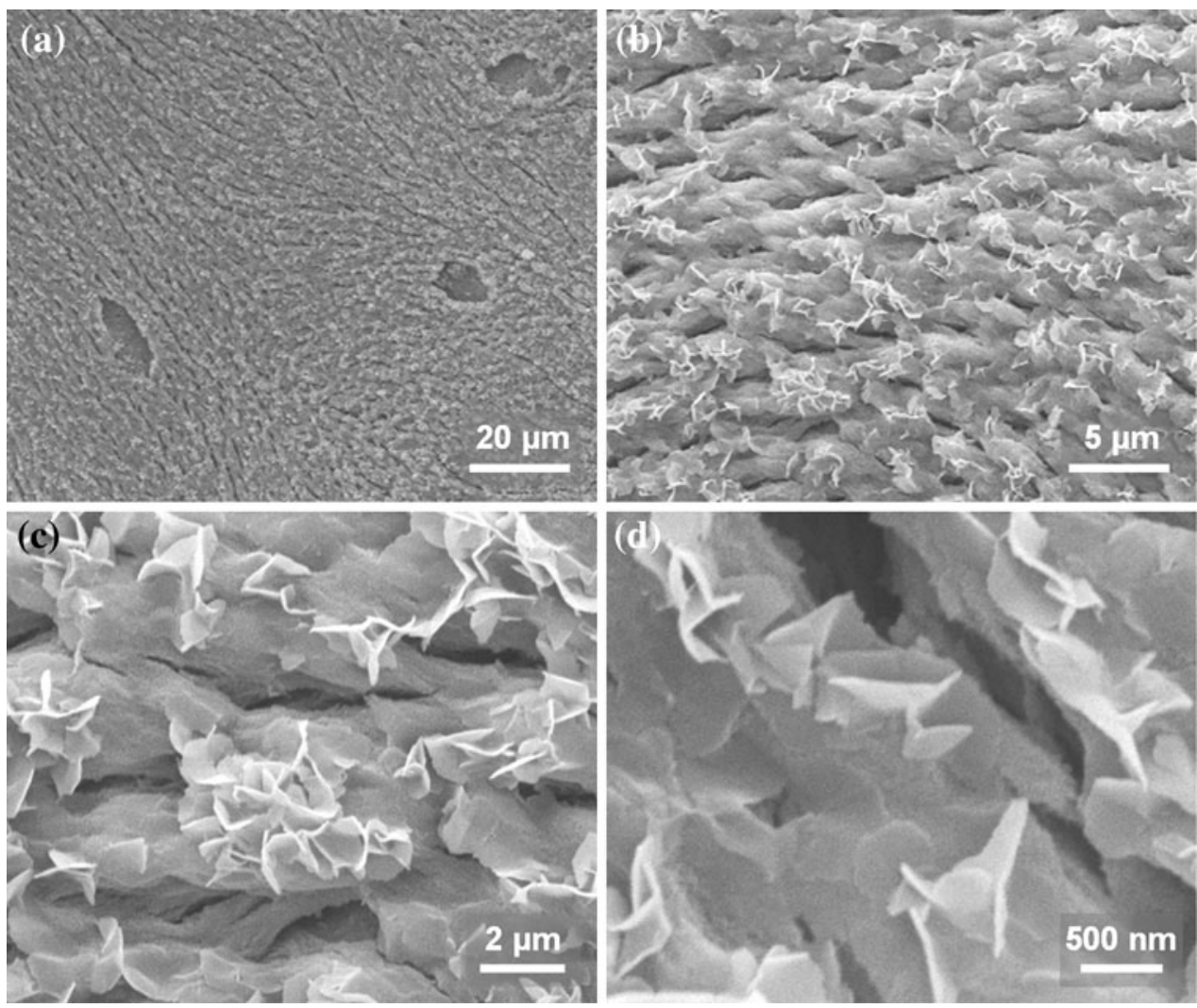

sheets were peeled off and folded after compressive deformation. The dimensions and morphology of the mineral sheets are in good agreement with the fracture surface shown in Fig. 5c, d. It is unlikely these mineral sheets were formed by reprecipitation since the samples were kept in constant agitation during the deproteinization process.

\section{Discussion}

There have been studies on the structure of deproteinized bone using chemical methods. Termine et al. [40] first proposed a deproteinization procedure by hydrazine, which is regarded as one of the most widely used and effective deproteinization methods. Recent studies by Bertazzo and Bertran [41], employing SEM, thermogravimetric analysis (TGA), X-ray diffraction (XRD), inductive coupled plasmaoptical emission spectroscopy (ICP-OES), C-H-N analysis, and Fourier transform infrared spectroscopy (FTIR) have shown that the hydrazine deproteinization procedure does not alter bone mineral composition and microstructure. The results showed that $<4 \%$ of the original organic components remained in bone after deproteinization. Thus, it is possible that the hydrazine deproteinization procedure proposed by Termine et al. [40] does not completely remove all the protein in bone. Another relatively mild deproteinization procedure uses $\mathrm{NaOCl}$ solution, which was applied in this study. Turner and coworkers $[42,43]$ used a $7-w t \% \mathrm{NaOCl}$ solution at room temperature for 3 days to remove protein constituents in bone and studied the mechanical anisotropy of both demineralized and deproteinized bones using scanning acoustic microscopy. In their studies, completion of deproteinization was verified by subsequent demineralization. However, no further protein analysis was applied to confirm whether or not there existed a small amount of protein. Here, we showed that our deproteinized bone samples did not contain protein within measurable limits $(<0.001 \%)$.

At the macrostructural level, deproteinized cancellous bone replicated the structural feature found in untreated and completely demineralized samples, as shown in the stereoscopic images (Fig. 2). The fine trabecular architecture and well-aligned channels in the longitudinal direction remained unaltered after removing all of the protein constituents, indicating structural integrity of the mineral constituents. This is in agreement with the macrostructure of Bio-Oss ${ }^{\circledR}[32,35]$.

The porosity in cancellous bone appears at several length scales [44]. At the millimeter scale, the bone has pores that are on the order of 1-3 mm, which are filled with blood in the live animal. The second length scale arises from the elliptically shaped lacunar spaces, where osteocytes (transformed 
from the bone-building osteoblasts) reside in the living bone, which are $\sim 10 \times 5 \mu \mathrm{m}$. The third scale involves the canaliculi, which are small tubules $(100 \mathrm{~nm}$ in diameter) extending from the lacunar spaces that transmit signals from one osteocyte to another. Finally, there is a small gap between the collagen molecules, on the order of $10 \mathrm{~nm}$, where water and/or the mineral phase can be found. Both deproteinized and demineralized samples show lacunar spaces and organized arrays of pores several hundreds of nanometers in diameter, which appear to be the canaliculi.

Fracture surfaces from compression tests of untreated (Fig. 4) and deproteinized (Fig. 5) cancellous bones were compared side by side at the same magnifications. Minerals were fused together, in the form of concentric sheet-like or plate-like structures, and aligned parallel to each other along the trabecula. The majority of minerals appeared to be outside of the collagen fibrils (interfibrillar mineral). It is possible that the intrafibrillar crystallites are lost during the deproteinization process as the collagen is being removed. The minerals are aligned and follow a certain orientation in a coherent manner with collagen, forming a continuous network. This observation is similar to the study on Bio-Oss ${ }^{\circledR}$ [37]. In SAXS studies, Jaschouz et al. [45] found a predominant parallel orientation of the $c$-axis of the mineral crystals with respect to the long axis of the trabecula and that the mineral crystals followed the plane of the lamellae. The mineral organization observed in our deproteinized samples is in agreement with the findings by Landis et al. [26, 27] and Jaschouz et al. [45].

The average thickness of the mineral sheets estimated from several edge-on oriented minerals is $\sim 20 \mathrm{~nm}$, which is five to ten times thicker than that of individual mineral crystallites $(1.5-4 \mathrm{~nm})$. The reported thickness of the mineral sheets of Bio-Oss ${ }^{\circledR}$ is $<10 \mathrm{~nm}$ [37]. It is possible that the thickness of mineral sheets in our samples is overestimated due to nonalignment issues.

Due to the resolution limit of the SEM, we could not distinguish whether the mineral sheet is a cluster of loosely connected mineral crystallites by van der Waals interactions or strongly chemical-bonded mineral platelets. However, the observation of folding and peeling off the mineral sheets after compressive deformation (Fig. 6) implies that the mineral crystallites are more likely fused together, with strong bonding between them. Otherwise, the mineral sheets would break apart into individual crystallites after deformation. An earlier study on bone mineral morphology by Weiner and Price [7] showed that in order to obtain individual mineral crystallites, grinding is required. This gives additional evidence that bone minerals are fused together.

The significant finding of this study is that mineral crystallites in mature bone are strongly fused together, forming a sheet-like structure. More interestingly, the mineral sheets demonstrate structural integrity, forming a continuous network, similar to the collagen matrix. This evidence supports our hypothesis and is in agreement with previous observations in heat-deproteinized bovine bone. It is possible that this structural integrity of minerals may not be observed at earlier stages of mineralization due to insufficient amounts of mineral required for such continuity. Previous studies of mineral organization based on mineralized tendon and partially mineralized bone at early stages of mineralization are not adequate to provide a structural model for fully mineralized mature bone. Benezra-Rosen et al. [37], based on structural characterization of heat-deproteinized Bio-Oss ${ }^{\circledR}$, suggested that the mineral phase, like the collagen matrix, is continuous. Mature bone is not an isolated mineral crystallite-reinforced collagen matrix composite. Indeed, mature bone must be considered as an interpenetrating composite of the collagen and the mineral constituents. By completely removing either phase, mature bone remains a self-supporting and continuous network. In order to better understand the hierarchical structure and mechanical properties of mature bone, a more realistic composite model must be applied. Our observations on bone mineral organization suggest that the mechanical properties of mature bone are not merely determined by the amount of mineral present but, more importantly, by the structural connection between mineral crystallites as well as the mineral-collagen interface.

In summary, the NaOCl-based method to completely remove protein from bulk mature bone has been verified down to a protein detection limit of $0.001 \%$. The hierarchical structure of bone mineral organization has been thoroughly investigated and compared with untreated and heat-deproteinized bone $\left(\right.$ Bio-Oss $\left.{ }^{\circledR}\right)$. Bone minerals are fused together in a sheet-like structure and form a continuous network in a coherent manner with collagen fibrils. Porous structure at varying length scales (vascular channels, osteocyte lacunae, canaliculi, etc.) is well preserved and unaltered after deproteinization. Based on the structural organization of the mineral constituents observed in this study, mature bone is indeed an interpenetrating composite of the mineral and the collagen constituents.

Acknowledgements We thank Evelyn York (Scripps Institution of Oceanography, San Diego, CA) and Ryan Anderson (CallT2) for their help on the optical and scanning electron microscopy. Discussions with Professors John Currey (University of York, York, UK) and John Skedros (University of Utah, Salt Lake City, UT) have been very helpful. Professor Marc A. Meyers is especially thanked for his valuable insights, enthusiasm for, and support of this project. This research is funded by the National Science Foundation, Division of Materials Research, Biomaterials Program (DMR 0510138), and Ceramics Program (DMR 1006931) as well as the Army Research Office (W911-08-1-0461). 
Open Access This article is distributed under the terms of the Creative Commons Attribution Noncommercial License which permits any noncommercial use, distribution, and reproduction in any medium, provided the original author(s) and source are credited.

\section{References}

1. Weiner S, Wagner HD (1998) The material bone: structuremechanical function relations. Annu Rev Mater Sci 28:271-298

2. Rho JY, Kuhn-Spearing L, Zioupos P (1998) Mechanical properties and the hierarchical structure of bone. Med Eng Phys 20:92-103

3. Currey JD (2002) Bones: structure and mechanics. Princeton University Press, Princeton, NJ

4. Fratzl P, Weinkamer R (2007) Nature's hierarchical materials. Prog Mater Sci 52:1263-1334

5. Olszta MJ, Cheng X, Jee SS, Kumar R, Kim Y-Y, Kaufman MJ, Douglas EP, Gower LB (2007) Bone structure and formation: a new perspective. Mater Sci Eng R 58:77-116

6. Jackson SA, Cartwright AG, Lewis D (1978) The morphology of bone mineral crystals. Calcif Tiss Res 25:217-222

7. Weiner S, Price PA (1986) Disaggregation of bone into crystals. Calcif Tissue Int 39:365-375

8. Ziv V, Weiner S (1994) Bone crystal sizes: a comparison of transmission electron microscopic and X-ray diffraction width broadening techniques. Connect Tissue Res 30:165-175

9. Boskey A (2003) Bone mineral crystal size. Osteoporos Int 14(Suppl 5):16-21

10. Fratzl P, Groschner M, Vogl G, Plenk H, Eschberger J, FratzlZelman N (1992) Mineral crystals in calcified tissues: a comparative study by SAXS. J Bone Miner Res 7:329-334

11. Watchtel E, Weiner S (1994) Small-angle X-ray scattering study of dispersed crystals from bone and tendon. J Bone Miner Res 9:1651-1655

12. Tong W, Glimcher MJ, Katz JL, Kuhn L, Eppell SJ (2003) Size and shape of mineralites in young bovine bone measured by atomic force microscopy. Calcif Tissue Int 72:592-598

13. Hassenkarm T, Fantner GE, Cutroni JA, Weaver JC, Morse DE, Hansma PK (2004) High-resolution AFM imaging of intact and fracture trabecular bone. Bone 35:4-10

14. Berthet-Colominas C, Miller A, White SW (1979) Structural study of the calcifying collagen in turkey leg tendons. J Mol Biol 134:431-445

15. Weiner S, Traub W, Wagner HD (1986) Lamellar bone: structure-function relations. J Struct Biol 126:241-255

16. Arsenault AL (1991) Image analysis of mineralized and nonmineralized type-I collagen fibrils. J Electron Microsc Tech 18:262-268

17. Erts D, Gathercole LJ, Atkins EDT (1994) Scanning probe microscopy of intrafibrillar crystallites in calcified collagen. J Mater Sci Mater Med 5:200-206

18. Landis WJ, Song MJ, Leith A, McEwen L, McEwen BF (1993) Mineral and organic matrix interaction in normally calcifying tendon visualized in three dimensions by high-voltage electron microscopic tomography and by graphic image reconstruction. J Struct Biol 110:39-54

19. Landis WJ, Hodgens KJ, Song MJ, Arena J, Kiyonga S, Marko M, Owen C, McEwen BF (1996) Mineralization of collagen may occur on fibril surfaces: evidence from conventional and highvoltage microscopy and three-dimensional imaging. J Struct Biol 117:24-35

20. Siperko LM, Landis WJ (2001) Aspects of mineral structure in normally calcifying avian tendon. J Struct Biol 135:313-332
21. Katz EP, Li S (1973) Structure and function of bone collagen fibrils. J Mol Biol 80:1-15

22. Bonar LC, Lees S, Mook HA (1985) Neutron diffraction studies of collagen in fully mineralized bone. J Mol Biol 181:265-270

23. Pidaparti RMV, Chandran A, Takano Y, Turner CH (1996) Bone mineral lies mainly outside collagen fibrils: predictions of a composite model for osteonal bone. J Biomech 29:909-916

24. Sasaki N, Tagami A, Goto T, Taniguchi M, Nakata M, Hikichi K (2002) Atomic force microscopic studies on the structure of bovine femoral cortical bone at the collagen fibril-mineral level. J Mater Sci Mater Med 13:333-337

25. Nikolov S, Raabe D (2008) Hierarchical modeling of the elastic properties of bone at submicron scales: the role of extrafibrillar mineralization. Biophys J 94:4220-4232

26. Landis WJ (1995) The strength of a calcified tissue depends in part on the molecular structure and organization of its constituent mineral crystals in their organic matrix. Bone 16:533-544

27. Landis WJ, Hodgens KJ, Arena J, Song MJ, McEwen BF (1996) Structural relations between collagen and mineral in bone as determined by high voltage electron microscopic tomography. Microsc Res Tech 33:192-202

28. Jäger I, Fratzl P (2000) Mineralized collagen fibrils: a mechanical model with a staggered arrangement of mineral particles. Biophys J 79:1737-1746

29. Gao HJ, Ji BH, Jäger IL, Arzt E, Fratzl P (2003) Materials become insensitive to flaws at nanoscale: lessons from nature. Proc Natl Acad Sci USA 100:5597-5600

30. Fratzl P, Gupta HS, Paschalis EP, Roschger P (2004) Structure and mechanical quality of the collagen-mineral nano-composite in bone. J Mater Chem 14:2115-2123

31. Gupta HS, Seto J, Wagermaier W, Zaslansky P, Beosecke P, Fratzl $\mathrm{P}$ (2006) Cooperative deformation of mineral and collagen in bone at the nano-scale. Proc Natl Acad Sci USA 103:17741-17746

32. Stavropoulos A (2008) Deproteinized bovine bone xenograft. In: Pietrzak WS (ed) Musculoskeletal tissue regeneration. Humana Press, Clifton, NJ, pp 119-151

33. Raspanti M, Guizzardi S, De Pasquale V, Martini D, Ruggeri A (1994) Ultrastructure of heat-deproteinated compact bone. Biomaterials 15:433-437

34. Carter DH, Scully AJ, Heaton DA, Young MPJ, Aaron JE (2002) Effect of deproteination on bone mineral morphology: implications for biomaterials and aging. Bone 31:389-395

35. Peetz M (1997) Characterization of xenogeneic bone materials. In: Boyne PJ (ed) Osseous reconstruction of the maxilla and mandible. Quintessence, Chicago, pp 87-93

36. Benke D, Olah A, Mohler H (2001) Protein-chemical analysis of Bio-Oss bone substitute and evidence on its carbonate content. Biomaterials 22:1005-1012

37. Benezra Rosen V, Hobbs LW, Spector M (2002) The ultrastructure of anorganic bovine bone and selected synthetic hydroxyapatites used as bone graft substitute materials. Biomaterials 23:921-928

38. Toroian D, Lim JL, Price PA (2007) The size exclusion characteristics of type I collagen: implications for the role of non-collagenous bone constituents in mineralization. J Biol Chem 282:22437-22447

39. Currey JD, Hughes SM (1973) The effects of pregnancy and lactation on some mechanical properties of the femora of the rat. Calcif Tissue Res 11:112-123

40. Termine JD, Eanes ED, Greenfie DJ, Nylen MU, Harper RA (1973) Hydrazine-deproteinated bone mineral-physical and chemical properties. Calcif Tissue Res 12:73-90

41. Bertazzo S, Bertran CA (2008) Effect of hydrazine deproteination on bone mineral phase: a critical review. J Inorg Biochem 102:137-145

42. Hasegawa K, Turner CH, Burr DB (1994) Contribution of collagen and mineral to the elastic anisotropy of bone. Calcif Tissue Int 55:381-386 
43. Takano Y, Turner CH, Owan I, Martin RB, Lau ST, Forwood MR, Burr DB (1998) Elastic anisotropy and collagen orientation of osteonal bone are dependent on the mechanical strain distribution. J Orthop Res 17:59-66
44. Cowin SC (1999) Bone poroelasticity. J Biomech 3:217-238

45. Jaschouz D, Paris O, Roschger P, Hwang HS, Fratzl P (2003) Pole figure analysis of mineral nanoparticle orientation in individual trabecula of human vertebral bone. J Appl Cryst 36:494-498 